\title{
Perfil dos Conselhos Municipais de Desenvolvimento Rural Sustentável no território Centro-Sul do Paraná
}

\author{
Nardel Luiz Soares da Silva ${ }^{1}$ \\ Igor Felipe Zampier ${ }^{2}$ \\ Inês Terezinha Pastório ${ }^{3}$ \\ Leoni Terezinha Wammes ${ }^{4}$ \\ Marcos Roberto Gregolin ${ }^{5}$ \\ Neimar Afonso Sornberger ${ }^{6}$
}

\section{Resumo}

Os Conselhos Municipais de Desenvolvimento Rural Sustentável (CMDRS) configuram-se como importantes espaços para a articulação dos pequenos agricultores nas decisões e discussões sobre o desenvolvimento rural regional. Dessa forma, o presente artigo apresenta um estudo de caso sobre os perfis dos CMDRS no território Centro-Sul do Paraná. Os conselhos estudados, em sua maioria, estão cumprindo o previsto pelo Conselho Nacional de Desenvolvimento Rural e Agricultura Familiar (CONDRAF), uma vez que são constituídos por lei ou decreto, possuem maior percentual de agricultores familiares como representantes, e são consultivos e deliberativos, tornando-se ativos nas decisões de seus municípios.

Palavras-chave: Políticas públicas. Desenvolvimento rural sustentável. Participação social.

\begin{abstract}
The Municipal Councils for Sustainable Rural Development (CMDRS), are configured as important spaces for the articulation of small farmers while deciding and discussing about Regional Rural Development. Thus the present article represents a case study on the CMDRS's profiles in Paraná's South Centered Territories. The studied councils, in its majority, are fulfilling with what was planned by the National Council of Rural Development and Family Agriculture (CONDRAF), since they are created by law or ordinance, having a bigger percentage of representatives among the farmers, and are consultative
\end{abstract}

\footnotetext{
${ }^{1}$ Doutor em Agronomia, coordenador do Programa de Pós-Graduação em Desenvolvimento Rural Sustentável - PPGDRS (UNIOESTE).

2 Engenheiro Agrônomo, Chefe do Núcleo Regional da SEAB de Irati.

${ }^{3}$ Assistente Social. Mestranda do Programa de Pós-Graduação em Desenvolvimento Rural Sustentável - PPGDRS (UNIOESTE).

${ }^{4}$ Assistente Social. Mestre em Desenvolvimento Rural Sustentável - PPGDRS (UNIOESTE).

${ }^{5}$ Comunicador Social. Mestrando do Programa de Pós-Graduação em Desenvolvimento Rural Sustentável - PPGDRS (UNIOESTE).

${ }^{6}$ Biólogo. Doutorando do Programa em Educação para a Ciência e Matemática (UEM).
} 
and deliberative; becoming active in their municipalities decisions.

Keywords: Public politics. Sustainable rural development. Social participation.

\section{Introdução}

Novas perspectivas surgem no Brasil para a gestão das políticas públicas e dos recursos naturais, as quais primam pela participação conjunta dos diferentes setores da sociedade na discussão, articulação e, consequentemente, na ação conjunta com os órgãos de gestão. A participação dos diferentes atores sociais nas decisões que afetam a sua vida surge em diversos espaços, ancorada por diretrizes políticas que visam a uma gestão democrática e a uma governança compartilhada das políticas e dos recursos que influenciam diretamente na vida da população, em especial das classes mais emergentes.

Cardoso e Ferreira (2011) inferem que, a partir da ECO-92 - Conferência das Nações Unidas sobre Meio Ambiente e Desenvolvimento, ocorrida no Rio de Janeiro, em 1992, surge um novo direcionamento para os países em desenvolvimento; a AGENDA 21, fruto da ECO-92, preconiza um conjunto de novas estratégias de governança, relocando os municípios como lugares de comando, gestão e planejamento de ações, tendo como base, para a tomada de decisões, a participação de todos os setores da sociedade.

O Brasil passa, então, a focar em um novo modelo de gestão para as políticas públicas, abrangendo novos espaços e ferramentas para o desenvolvimento local, delegando aos municípios um papel maior na gestão das políticas. Nesse contexto, identificase uma necessidade de criar novos espaços que sejam participativos e que colaborem para a prática de uma nova democracia, pautada no empoderamento dos municípios e no controle social sobre o estado; surgindo, então, os Conselhos, os Comitês e demais espaços participativos.

Faz-se necessário lembrar que os movimentos pela democratização/redemocratização do país culminam na promulgação da Constituição de 1988 como resposta à repressão do período de ditadura militar. Este cenário se constitui num fértil solo para a proposição de mudanças e a articulação de políticas estruturantes de uma nova forma de governo, com distribuição de papéis e poderes de modo descentralizado.

De forma geral, os conselhos foram vistos como uma nova ferramenta democrática para permitir uma redistribuição de papéis em termos de tomada de decisão na sociedade. Como resposta aos aproximadamente vinte anos de centralização do regime militar, a descentralização constituiu uma reivindicação vigorosa, particularmente expressa na Constituição de 1988. O nível local de poder, na medida de sua proximidade com os cidadãos, tornava-se essencial na perspectiva democrática (MARQUES; FLEXOR, 2006, p. 51).

Dentro do processo de gestão democrática brasileira, os conselhos passam a ter um papel primordial junto às diferentes políticas sociais. Alencar et al. (2013, p. 113) afirmam que "[...] os conselhos de políticas públicas são colegiados cuja finalidade é promover o diálogo entre sociedade civil e poder público para a formulação, gestão ou controle de políticas públicas". 
Nas políticas agrícolas, os Conselhos Municipais de Desenvolvimento Rural Sustentável (CMDRS) são os espaços participativos, próprios para discussões e controle da aplicabilidade dos recursos destinados a esta política, bem como à promoção das articulações referentes ao desenvolvimento rural sustentável de cada município. Os CMDRS serão compostos por representantes do poder público municipal, das organizações dos agricultores familiares, dos beneficiários do Programa Nacional da Reforma Agrária, das organizações da sociedade civil e das entidades parceiras; dessa forma, configuram-se como importantes espaços para a articulação dos pequenos agricultores nas discussões e decisões sobre o desenvolvimento rural municipal (BRASIL, 2000).

\section{Conselhos Municipais de Desenvolvimento Rural Sustentável}

Legalmente, os CMDRS são mencionados na Lei no 1.946, de 28 de junho de 1996, que institui os Programas Nacionais da Agricultura Familiar (PRONAF). Também são previstos e definidos no Capítulo IV do Decreto no 3.508, de 14 de junho de 2000, que dispõe sobre o Conselho Nacional de Desenvolvimento Rural Sustentável (CNDRS), atualmente denominado Conselho Nacional de Desenvolvimento Rural e Agricultura Familiar (CONDRAF).

Inicialmente, estes Conselhos foram reconhecidos apenas como CMDR - Conselhos Municipais de Desenvolvimento Rural (BRASIL 1996); porém, com o advento do termo sustentabilidade, aliado à constatação da evidente relação entre a agricultura familiar e a temática, foi proposta pelo CONDRAF a utilização da nomenclatura CMDRS - Conselhos Municipais de Desenvolvimento Rural Sustentável. Assim sendo, as duas nomenclaturas são encontradas nos municípios brasileiros que instituíram conselhos de desenvolvimento rural, porém, para fins deste trabalho, utilizaremos a denominação CMDRS, sem questionar possíveis divergências do termo sustentabilidade entre elas.

Segundo o Título IV do Decreto no 3.508, que dispõe sobre o Conselho Nacional de Desenvolvimento Rural Sustentável (CNDRS), os municípios poderão instituir os Conselhos que devem deliberar sobre os Planos Municipais de Desenvolvimento Rural Sustentável, promovendo:

I - a articulação e a adequação de políticas públicas estaduais e federais à realidade municipal;

II - a compatibilização da programação físico-financeira anual dos Programas que integram o PNDRS e o Plano Estadual, acompanhar seu desempenho e apreciar os relatórios de execução;

III - os impactos das ações dos programas no desenvolvimento municipal e propor redirecionamentos;

IV - outras atribuições que lhe forem cometidas (BRASIL, 2000).

Marques e Flexor (2006) salientam que os CMDRS e a emergência de ideias em torno do desenvolvimento sustentável e do movimento ambientalista fomentam a participação social. Afinal, todos buscam o fortalecimento local, e o tomam como fundamental para alavancar os problemas e a busca de soluções na realidade dos atores sociais 
envolvidos.

Observa-se, então, que os CMDRS surgem como importantes ferramentas de participação dos atores do campo nas decisões correlatas ao desenvolvimento rural municipal, além de se constituírem como espaços de controle e gestão social, cujo objetivo principal é a construção, priorização, adequação e aprimoramento das políticas públicas a partir das demandas estabelecidas nos municípios (BAHIA, 2013), além de contribuir para a gestão e o controle dos recursos advindos de políticas públicas voltadas ao meio rural.

A partir destes aspectos, o presente trabalho objetivou caracterizar o perfil dos CMDRS do território Centro Sul do Paraná, suas potencialidades, deficiências e as dificuldades encontradas para compor espaços reais para o exercício de uma democracia participativa.

\section{Aspectos metodológicos}

A presente pesquisa se caracteriza como um estudo de caso, o qual pode ser definido como um esforço profundo e exaustivo que, segundo Gil (2008), permite o conhecimento amplo e detalhado dos poucos objetos estudados. Nesse sentido, foram analisadas as informações dos Conselhos Municipais de Desenvolvimento Rural Sustentável que integram os limites geográficos do território Centro-Sul do Paraná.

O território Centro-Sul do Paraná está localizado no segundo planalto paranaense e abrange uma área de $9.856,17 \mathrm{~km}^{2}$, o que corresponde a 4,9\% da área total do estado, sendo composto pelos municípios de Fernandes Pinheiro, Guamiranga, Imbituva, Inácio Martins, Ipiranga, Irati, Ivaí, Mallet, Prudentópolis, Rebouças, Rio Azul e Teixeira Soares (IPARDES, 2007).

De acordo com Gregolin et al. (2013), o processo de constituição do território Centro-Sul foi fundamentado na participação das comunidades e seus cidadãos, bem como na discussão da realidade e proposições de mudanças. O embrião dessas discussões pode ser temporalmente alocado em 1996, ano este em que foram constituídos os Conselhos Municipais de Desenvolvimento Rural em Rebouças e Inácio Martins. Há que se referenciar o papel importante e condicionante do Instituto EMATER neste cenário, o qual realizou várias capacitações com os agricultores dos municípios na ocasião da formação dos conselhos. Nesse sentindo, falar que o território foi constituído pela vontade e participação das comunidades também é afirmar a importância do órgão de ATER estadual, presente em todos os municípios do território e com ações articuladas em todos eles.

Segundo o Ministério do Desenvolvimento Agrário - MDA (2003, p. 34), território é:

[..] um espaço físico, geograficamente definido, geralmente contínuo, compreendendo a cidade e o campo, caracterizado por critérios multidimensionais - tais como o ambiente, a economia, a sociedade, a cultura, a política e as instituições - e uma população com grupos sociais relativamente distintos, que se relacionam interna e externamente por meio de processos específicos, onde se pode distinguir um ou mais elementos que indicam identidade e coesão social, cultural e territorial. 
Geograficamente, o território Centro-Sul pode ser identificado por diversas características, das quais se referencia o rico potencial aquífero, pois em sua área se encontram três importantes bacias hidrográficas, Iguaçu, Ivaí e Tibagi; a predominância do Bioma Floresta Ombrófila Mista (Floresta Nacional da Araucária), que, mesmo apresentando expressivos sinais de degradação, ainda atribui adjetivos ao território, como, por exemplo, "Terra dos Pinheirais".

A predominância da agricultura familiar é outro fator gerador de identidade no território Centro-Sul. Nos municípios que o compõem, existem mais de 21 mil estabelecimentos de agricultura familiar, número este que corresponde a $88,5 \%$ dos estabelecimentos totais. Este segmento, expressivo em quantidade de estabelecimentos, desfruta de $45,2 \%$ das terras, ao passo que a agricultura não familiar representa $11,5 \%$ dos estabelecimentos e ocupa 54,8 \% das terras (IBGE, 2013). Cabe ressaltar a importância da cultura do tabaco na região, sendo Inácio Martins o único município do território sem atrelamento econômico com este cultivo.

Os dados foram coletados através de um questionário pré-codificado, com perguntas fechadas e abertas, o qual foi encaminhado, via malote institucional, aos escritórios locais do Instituto Paranaense de Assistência Técnica e Extensão Rural- EMATER - de cada município integrante do referido território. Os questionários foram aplicados pelos técnicos locais que acompanham os CMDRS. Junto ao questionário, foi encaminhado um ofício explicativo sobre a pesquisa e o Termo de Consentimento Livre e Esclarecido, o qual foi assinado pelo técnico e pelo presidente do Conselho.

As análises dos dados foram realizadas através de uma abordagem quali-quantitativa. Na visão de alguns autores, as pesquisas devem ter abordagens únicas, ou seja, as pesquisas devem ser quantitativas ou qualitativas. Contudo, nas afirmações de Gerhardt e Silveira (2009), tanto a pesquisa quantitativa quanto a qualitativa exibem diferenças, com pontos fracos e fortes, porém ambas se completam. Diante disso, optou-se por ambas as abordagens.

\section{0 perfil dos Conselhos Municipais de Desenvolvimento Rural Sustentável}

\subsection{Aspectos legais dos CMDRS do Centro-Sul do Paraná}

Em relação à legalidade dos conselhos, um aspecto considerado fundamental é a maneira como são instituídos. As possibilidades são duas, por lei ou decreto. A criação por meio de lei é um aspecto que torna os conselhos mais efetivos, tornando-os um instrumento de controle e gestão das políticas públicas.

Dessa forma, verificou-se que $70 \%$ dos CMDRS afirmaram possuir lei de criação, enquanto $20 \%$ alegam não a possuir (Figura 1, inserida na próxima página). Destaca-se que, para serem reconhecidos legalmente, os CMDRS precisam encaminhar a lei ou decreto de criação, bem como o decreto de nomeação dos membros para a secretaria executiva do Conselho Estadual de Desenvolvimento Rural, mais especificamente, no Paraná, ao ConseIho Estadual de Desenvolvimento Rural e Agricultura Familiar (CEDRAF). Essa regulamentação proporciona legitimidade ao Conselho e às suas deliberações, no entanto constatou-se que 
nem todos os conselhos pesquisados atendem a este requisito, ou seja, os conselhos que não possuem a referida regulamentação não estão legitimados.

Assim, a criação por decreto ou lei parece não gerar diferenciações, contudo, um conselho criado por decreto, literalmente passa a existir por meio de uma assinatura do poder executivo, e, consequentemente, pode passar a não existir pelas mesmas mãos. Um conselho constituído por meio de lei, ao menos no papel, tem mais segurança de existir, podendo ficar livre para deliberar a favor ou contra o poder executivo, haja vista que sua regulamentação deu-se pelo movimento também do poder legislativo. Porém, infere-se aqui que essas situações ficam suscetíveis à conjuntura de cada município, podendo haver diferentes situações, tendo por base os atores envolvidos no processo.

Figura 1 - Institucionalização dos Conselhos

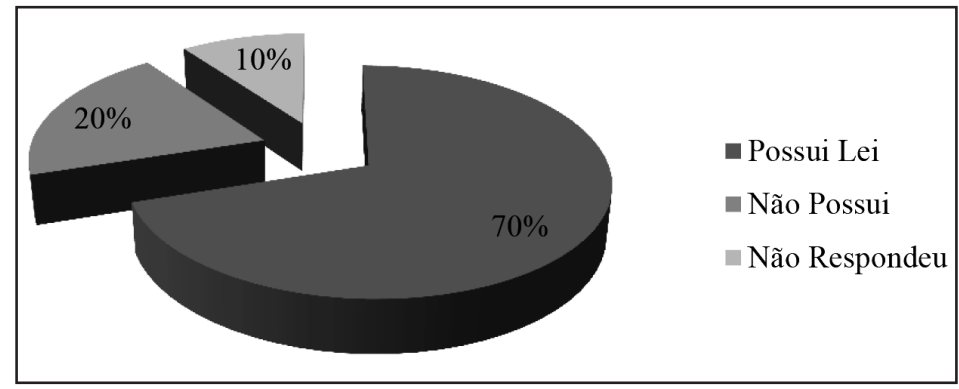

Fonte: elaborado pelos autores.

Outro aspecto a ser tratado é a maneira pela qual os conselheiros são nomeados. A nomeação dos membros de um conselho municipal pode demonstrar a maneira pela qual a sociedade civil e o poder público são representados, e interferem, positiva ou negativamente, nos rumos e decisões do conselho. Constatou-se que $60 \%$ dos conselhos pesquisados sabiam da existência de um decreto de nomeação (Figura 2). O percentual de conselhos cujos representantes não conhecem como ocorre a nomeação de seus integrantes pode constituir-se numa evidência reveladora da fragilidade destes órgãos e do baixo controle social que eles podem exercer, haja vista que o não conhecimento da legalidade pela qual são constituídos pode implicar no não conhecimento e no não exercício das atribuições que lhe são garantidas.

Figura 2 - Processo de nomeação dos Conselheiros, 2013

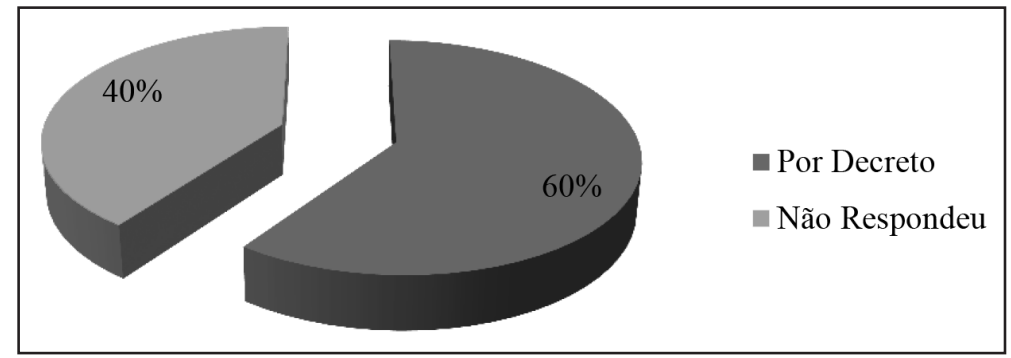

Fonte: elaborado pelos autores. 
Os decretos de nomeação podem ser abertos ou fechados, tomando por exemplo dois casos da amostra. Em um deles, o decreto é atualizado a cada mandato, com o nome das pessoas indicadas pelo poder público para ocupar as cadeiras do conselho. Não foram obtidas informações sobre como esses nomes são escolhidos, se pela comunidade, em conferências, ou se unicamente pela vontade do executivo. O outro exemplo pode ser considerado como decreto aberto, ou seja, um decreto único, com os nomes dos membros por setor.

Os conselheiros do poder público são escolhidos dentro das instituições, e os conseIheiros das comunidades são escolhidos nas associações. $O$ decreto apenas regulamenta que o presidente de cada associação é, automaticamente, o representante da mesa no CMDRS.

Quanto ao caráter de decisão dos conselhos, estes podem ser consultivos, deliberativos ou propositivos, podendo também acumular mais de uma dessas características, ou não possuír nenhuma. A resolução do CONDRAF sugere em seu Art. 3:ㅜㅇ

[...] que os Conselhos tenham um caráter norteador, referenciador e definidor do processo de desenvolvimento rural sustentável, sendo, para isso, necessário o reconhecimento, pelos atores governamentais e da sociedade organizada, como espaços legítimos de decisões ou formulações efetivamente consideradas em torno das políticas, programas e projetos relevantes e estratégicas nos diferentes níveis - federal, estadual, territorial e municipal (BRASIL, 2004).

Neste sentido, esta diferenciação é definida na lei da criação de cada conselho, na qual pode se restringir ou não o seu papel e sua atuação.O caráter do conselho é uma das características fundamentais no desempenho do controle social e gestão de políticas públicas; contudo, de acordo com o entendimento de Gohn (2000, p. 180), essa prática não é muito identificada em campo.

Apesar da legislação incluir os conselhos como parte do processo de gestão descentralizada e participativa, e contitituí-los como novos atores deliberativos e paritários, vários pareceres oficiais têm assinalado e reafirmado o caráter apenas consultivo dos conselhos, restringindo suas ações ao campo da opinião, da consulta e do aconselhamento, sem poder de decisão ou deliberação.

Ainda de acordo com Gohn (2000), mesmo o conselho tendo um caráter deliberativo, isso não lhe dá garantias de que tenha suas proposições acatadas e implementadas pelo poder público, uma vez que não há um aparato jurídico-legal que ampare as decisões dos conselhos e as tornem obrigatórias. Constatou-se que $40 \%$ deles são puramente deliberativos, e $40 \%$ deliberativos e consultivos; entretanto, $10 \%$ dos conselhos estudados são, formalmente, apenas consultivos (Figura 3, inserida na próxima página). 
Figura 3 - Classificação dos CMDRS por caráter de decisão

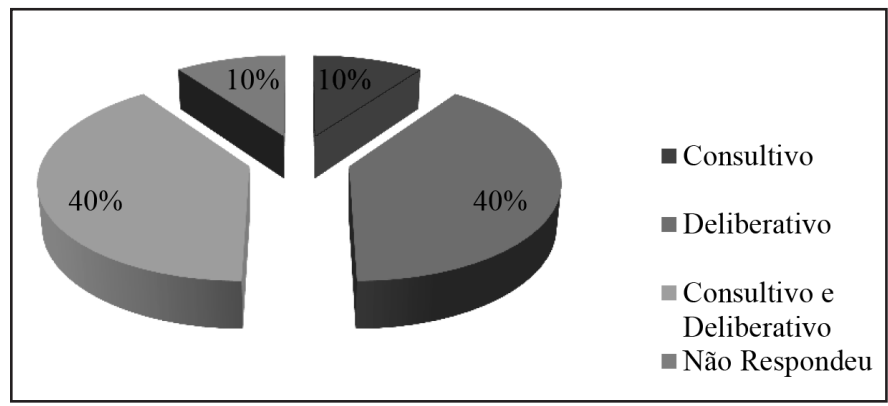

Fonte: elaborado pelos autores.

\subsection{Da composição}

Segundo o Artigo 15 do Decreto no 3.508/00, os CMDRS serão compostos por representantes do poder público municipal, das organizações dos agricultores familiares, dos beneficiários do Programa Nacional da Reforma Agrária, das organizações da sociedade civil e das entidades parceiras (BRASIL, 2000), definindo também "[...] a paridade entre os membros do poder público municipal e da sociedade civil".

De acordo com o CONDRAF, os CMDRS devem ter uma composição representativa, como disposto no Art. 4ㅇ: "Recomendar uma composição representativa, diversa e plural dos atores sociais relacionados ao desenvolvimento rural". A aplicação dessa recomendação pode ser contextualizada pela Figura 4, a qual demonstra a diversidade dentro dos CMDRS analisados.

Souza e Caume (2008, p. 3) enfatizam que os CMDR devem ser compostos "[...] por agricultores familiares, representantes do poder público e de entidades parceiras", e apontam que estes conselhos se tornam "[...] espaços institucionalizados de discussões, decisões de políticas públicas sobre o rumo e os caminhos que podem ser seguidos para melhorar as condições de vida da população rural".

Constatou-se que, nos Conselhos Municipais pesquisados, $67 \%$ dos conselheiros são agricultores familiares (Figura 4); contudo, de acordo com o entendimento de Moura (2007), o fato de um CMDRS possuir 50\% ou maior número de representantes de agricultores familiares não exclui a possibilidade de manipulação por parte do poder público. Esta manipulação pode ocorrer por meio do poder de argumentação ou de articulação dos representantes governamentais, ou mesmo pela indicação de representantes de agricultores vinda do poder público.

Souza (2008) infere que o simples fato de existir paridade numérica entre os representantes do poder público e os dos agricultores familiares por si só não confere legitimidade às deliberações realizadas no âmbito dos Conselhos.

Diante disso, Tommasi (1997, apud Souza, 2008, p. 256) sugere ir além, pois “[...] a efetiva paridade envolve a aquisição de competência dos atores envolvidos, a qual se constrói em função do acesso às informações e às oportunidades de formação" para que haja equidade nas deliberações dos conselhos.

Tendo por base os dados obtidos de constituição dos conselhos, pode-se concluir 
que $78 \%$ dos representantes são oriundos da sociedade civil, ao passo que $22 \%$ representam o poder público, tendo mais presença o poder público municipal, seguido pelo estadual e, por fim, o federal.

\section{Figura 4 - Perfil dos Conselheiros dos CMDRS}

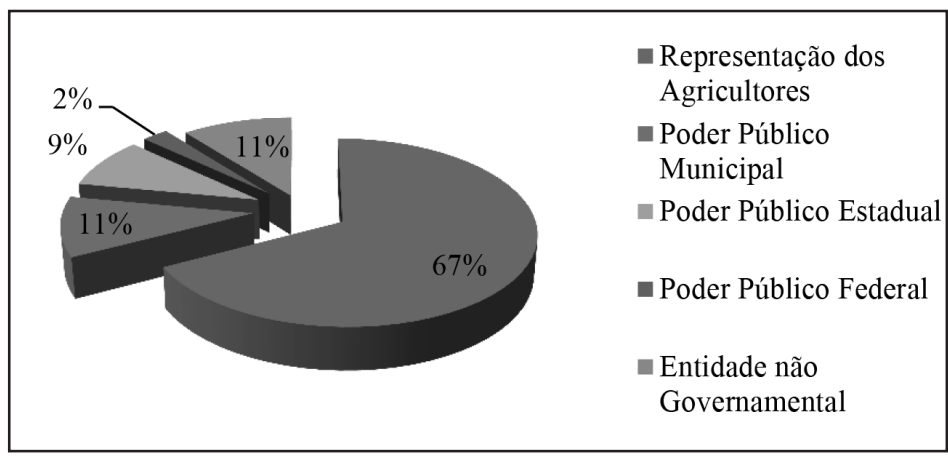

Fonte: elaborado pelos autores.

A Figura 5, mostra-nos dados referentes aos presidentes dos conselhos pesquisados, os quais indicam que $70 \%$ são presididos por agricultores enquanto $20 \%$, por representantes do governo municipal, e 10\% por organizações não governamentais.

\section{Figura 5 - Perfil dos Presidentes dos CMDR}

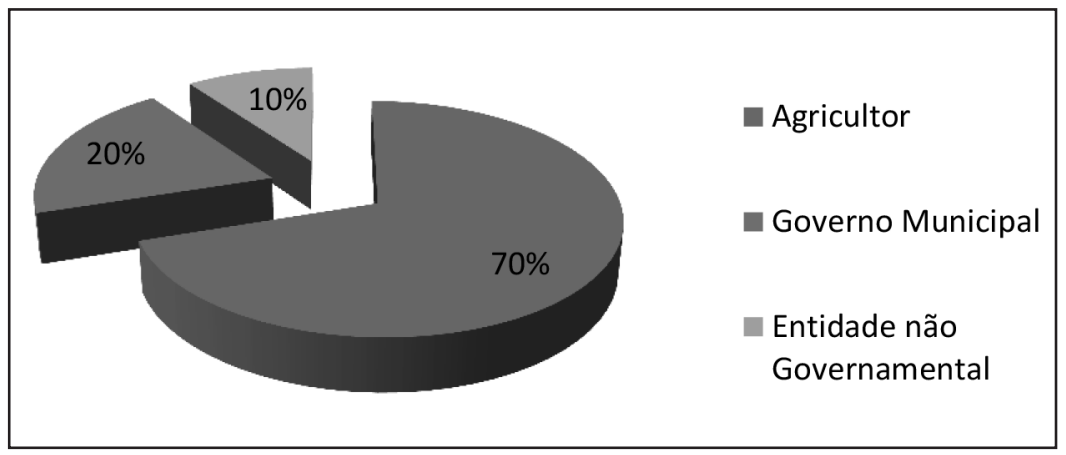

Fonte: elaborado pelos autores.

Em alguns casos, os CMDRS são presididos por representantes do governo municipal; outros, por secretários da agricultura ou técnicos da EMATER. Conforme Moura (2007), esta situação pode ser atribuída ao fato de que esses atores possuem tempo remunerado para se dedicar às atividades referentes aos conselhos e a sua gestão, os quais são considerados agentes com mais competência técnica para lidar com a burocracia e o funcionamento dos conselhos.

Da mesma maneira, verificou-se que grande parte dos presidentes são representantes dos agricultores familiares, geralmente secretariados por representantes de instituições públicas, os quais dispõem de mais recursos teóricos e práticos para articular e 
encaminhar a burocracia e legalidades referentes aos CMDRS (Figura 5).

A participação dos agricultores, juntamente com a participação do poder público, no processo decisório, na direção e na gestão das políticas públicas, abre novas possibilidades para o desenvolvimento local, pois permite que sejam conhecidas as reais necessidades da agricultura familiar, e também que as soluções sejam compatíveis com a realidade local.

De acordo com o CONDRAF, os CMDRS devem ter uma composição representativa, conforme já foi citado. Contudo, as funções dentro do conselho devem ser acessíveis a todos os membros, conforme explicita o Art. 4으, inciso IV, "[...] que a Presidência seja exercida por qualquer órgão/entidade integrante dos Conselhos de Desenvolvimento Rural Sustentável, a partir da definição dos próprios Conselheiros" (BRASIL, 2004), efetivando, dessa forma, uma composição diversa e plural, dando oportunidades para vários segmentos representativos assumirem a liderança.

\section{Considerações finais}

Constatou-se, com base no estudo realizado, que os conselhos, por mais fragilizados que possam estar, são espaços onde os agricultores têm respaldo nas tomadas de decisões e podem opinar sobre os rumos das políticas públicas, fazendo valer a democracia. Esses conseIhos se configuram como importantes espaços que oportunizam o controle social de recursos destinados ao município para o desenvolvimento rural sustentável. Os que foram objeto desta pesquisa, em sua maioria, não se encontram em conformidade com o que preconiza a lei. Contudo é salutar a lembrança de que, por si só, a institucionalização de conselhos municipais representa um grande avanço, pois constituem espaços onde a população pode ter voz e vez.

Em municípios cujos conselhos são atuantes, os recursos são aplicados em demandas reais, pois o destino da aplicação é discutido e deliberado de forma democrática e participativa, contribuindo para o controle social. Tal situação justifica a criação de um espaço cujo objetivo primordial é promover a descentralização do poder de decisão e a participação nas decisões sócio-políticas e econômicas dos recursos destinados aos municípios.

\section{Referências}

ALENCAR, J. et al. Participação social e desigualdades nos conselhos nacionais. Sociologias, Porto Alegre, v. 15, n. 32, p. 112-146, jan./abr. 2013. Disponível em: <http://www.ipea.gov.br/participacao/images/pdfs/participacao/artigo\%20sociologias. pdf>. Acesso em: 14 mar. 2015.

BAHIA. Secretaria da Agricultura, Pecuária, Irrigação, Reforma Agrária, Pesca e Aquicultura. SEAGRI. Conselho Municipal de Desenvolvimento Sustentável - CMDS. 2013. Disponível em: <http://w ww.seagri.ba.gov.br/sites/default/files/CARTILHA_CMDS_2013.pdf>. Acesso em: 14 fev. 2015. 
BRASIL. Constituição da República Federativa do Brasil. Diário Oficial da União, Poder Executivo, Brasília, DF, 5 de outubro, 1988. p. 1 (ANEXO). Disponível em: <http://www.planalto.gov.br/ccivil_03/constituicao/constituicaocompilado.htm>. Acesso em: 14 jun. 2014.

. Decreto no 1946, de 28 de junho de 1996. Diário Oficial da União, Poder Executivo, Brasília, DF, 1 agosto, 1996. p. 11854. Disponível em: <http://www.planalto.gov.br/ccivil_03/decreto/D1946.htm>. Acesso em: 14 jun. 2014.

Decreto $n$ o 3.508, de 14 de junho de 2000. Diário Oficial da União, Poder Executivo, Brasília, DF, 15 junho, 2000. p. 1. Disponível em:

<http://www.planalto.gov.br/ccivil_03/decreto/D3508.htm>. Acesso em: 15 jun. 2014.

. Resolução no 48, de 16 de setembro de 2004. Ministério do Desenvolvimento Agrário. Diário Oficial da União, Poder Executivo, Brasília, DF, 23 setetembro 2004. Seção 01, p. 113. Disponível em: <http://portal.mda.gov.br/portal/condraf/arquivos/ view/resolu-es-condraf/48.\%20Diretrizes\%20e\%20Atribui\%C3\%A7\%C3\%B5es\%20 Redes\%20de\%20Conselhos\%20DRS\%202004.\%20(formato\%20pdf).pdf>. Acesso em: 14 jun. 2014.

CARDOSO, J. L.; FERREIRA, J. A. Conselhos e Planos Municipais de Desenvolvimento Rural Sustentável: alguns comentários. 2011. Disponível em:

<http://www.alasru.org/wp-content/uploads/2011/12/21-GT-Jo\%23U00e3o-LuizCardoso-Joaquim-Alves-Ferreira.doc>. Acesso em: 14 jun. 2014.

GERHARDT, Tatiana Engel; SILVEIRA, Denise Tolfo. Métodos de Pesquisa. Porto Alegre: UFRGS, 2009.

GIL, A. C. Métodos e Técnicas de Pesquisa Social. 6. ed. São Paulo: Atlas, 2008.

GOHN, M. G. O papel dos conselhos gestores na gestão urbana. Consejo Latino americano de Ciencias Sociales Editorial/Editor. Buenos Aires, 2000. Disponível em: <http://biblioteca.clacso.edu.ar/ar/libros/urbano/gohn.pdf>. Acesso em: 17 jun. 2014.

GREGOLIN, M. R. P. et al. Análise da aplicação dos recursos do programa nacional de desenvolvimento sustentável de territórios rurais no Centro Sul do Paraná. In: Jornada Questão Agrária e Desenvolvimento, 2013, Curitiba. 2a Jornada Questão Agrária e Desenvolvimento: Projetos Sociais e Políticas Públicas em Disputa, 2013.

IBGE. Instituto Brasileiro de Geografia e Estatística. Censo Agropecuário. Disponível em: <www.sidra.ibge.gov.br>. Acesso em: 20 out. 2013.

IPARDES. Instituto Paranaense de Desenvolvimento Econômico e Social. Diagnóstico Socioeconômico do Território Centro-sul Estado do Paraná. Curitiba, 2007. Disponível em: <http://www.ipardes.gov.br/webisis.docs/territorio_centro_sul.pdf>. Acesso em: 17 jun. 2014.

MARQUES, P. E. M.; FLEXOR, G. Conselhos Municipais e Políticas Públicas de Desenvolvimento Rural: indagações em torno dos papéis sociais e ambientais da agricultura. In: Políticas Públicas: reflexões em transversalidade (dossiê no 2). 2006. Disponível em: <http://www.redesrurais.org.br/sites/default/files/imagesfile/dossies/ Dossie_02.pdf>. Acesso em: 14 dez. 2014. 
MINISTÉRIO DO DESENVOLVIMENTO AGRÁRIO. MDA. Referências para o desenvolvimento territorial sustentável. Brasília: CONDRAF; NEAD, 2003.

MOURA, J. T. Vaz de. Os Conselhos Municipais de Desenvolvimento Rural e a Construção Democrática: esfera pública de debate entre agricultores familiares e o Estado. Revista Eletrônica Organizações Rurais \& Agroindustriais. v. 9, n. 2. 2007. Disponível em: <http://200.131.250.22/revistadae/index.php/ora/article/view/115>. Acesso em: 3 mar. 2015.

SOUZA, C. B. Políticas públicas e participação social feminina: a experiência dos Conselhos Municipais de Desenvolvimento Rural Sustentável. In: Sociedade e Cultura, v. 11, n. 2, jul./dez. 2008. Disponível em: <www.revistas.ufg.br/index.php/fchf/article/ download/5286/4325>. Acesso em: 14 abr. 2015.

SOUZA, C. B.; CAUME, D. J. Crédito Rural e Agricultura Familiar no Brasil. Evento da Sociedade Brasileira de Economia, Administração e Sociologia Rural. Rio Branco - Acre, 20 a 23 de julho de 2008. Disponível em: <http://www.sober.org.br/palestra/9/882. pdf>. Acesso em: 14 mar. 2015. 